\title{
AGROINDÚSTRIAS FAMILIARES, MERCADOS INSTITUCIONAIS E EMPODERAMENTO DAS MULHERES: Uma discussão a partir de Santana do Livramento/RS
}

\section{FAMILY AGRO-INDUSTRIES, INSTITUTIONAL MARKETS AND WOMEN'S EMPOWERMENT: a discussion from Santana do Livramento/RS}

\author{
Vanessa Lutke \\ Bacharel em Desenvolvimento Rural e Gestão Agroindustrial, UERGS, unidade \\ Santana do Livramento \\ vanessa.lutke@gmail.com \\ Cassiane da Costa \\ Professora da UERGS, unidade Santana do Livramento \\ professoracassianeuergs@gmail.com
}

\section{Resumo}

Atualmente são discutidas diversas questões que envolvem as agroindústrias familiares rurais (AFR). Aqui, nos propomos estudar a relação entre a comercialização dos produtos através dos mercados institucionais e a possível contribuição ao empoderamento das mulheres. Assim, esse artigo tem como objetivo estudar a participação das agroindústrias familiares rurais nos mercados institucionais do município de Santana do Livramento/RS, relacionando-as com o empoderamento das mulheres proprietárias dessas agroindústrias. Para tanto, utilizamos o Método de Estudo de Caso. Foram entrevistadas cinco proprietárias de AFR no município. Os resultados indicam a satisfação e a intenção das mulheres em comercializar através dos mercados institucionais, mas ressaltam que a operacionalização precisa de aperfeiçoamento. As agroindústrias contribuem para o empoderamento das mulheres, porém trazem um aumento da jornada de trabalho que afeta outras questões voltadas à sua qualidade de vida. Por fim, entendemos que os mercados institucionais têm grande potencial para promover o empoderamento das mulheres envolvidas em agroindústrias familiares rurais, principalmente se a agroindústria familiar de caráter emancipatório for promovida.

Palavras-chave: Agroindústria familiar rural. Mulheres. Empoderamento. Mercados institucionais.

\section{Abstract}

Nowadays, many issues involving rural family agro-industries (RFAs) are addressed. Here, we propose to study the relationship between the commercialization of products through institutional markets and its likely contribution for women's empowerment. 
Thus, this article aimed to study the participation of rural family agro-industries in institutional markets from Santana do Livramento/RS, Brazil, relating it to the empowerment of women who own these agro-industries. Therefore, we carried out a case study and interviewed five RFAs owners in the city. The results show the satisfaction and intention of women in commercializing through institutional markets, but emphasize that operationalization needs improvement. Agro-industries contribute to women's empowerment, despite rising working hours, then affecting other issues that impact their quality of life. Eventually, we understand that institutional markets have great potential to promote the empowerment of women involved in rural family agroindustries, especially if the emancipatory family agro-industries is promoted.

Keywords: Rural family agro-industry. Women. Empowerment. Institutional markets.

\section{Introdução}

O espaço rural do Brasil vem passando, nas últimas décadas, por muitas transformações. Nesse "Novo Rural", uma das caraterísticas é a aposta de muitas famílias na pluriatividade, combinação da prática da agricultura com outras atividades, dentro ou fora da unidade produtiva (SCHNEIDER, 1999) como estratégia de reprodução social. Nesse contexto, muitas agroindústrias familiares rurais vêm se formalizando, buscando agregar valor à produção das famílias de agricultores e o acesso a novos mercados. Para Mior (2003, p.178), agroindústria familiar rural (AFR) "é uma forma de organização onde a família rural produz, processa e/ou transforma parte de sua produção agrícola e/ou pecuária, visando sobretudo a produção de valor de troca que se realiza na comercialização". Também caracterizam as AFR aspectos como a localização no rural e a maior parte do trabalho ser realizado pela família, etc (MIOR, 2005). Assim, as agroindústrias familiares rurais têm papel importante para a agricultura familiar e para o desenvolvimento dos territórios rurais.

O município de Santana do Livramento/RS, que se localiza na Fronteira Oeste do Rio Grande do Sul, a $500 \mathrm{~km}$ da capital Porto Alegre, repercute essas mudanças. Os (as) agricultores (as) familiares têm buscado diversificar sua produção, na busca de agregar maior renda e melhorar a qualidade de vida de suas famílias. Na última década, foram formalizadas nove agroindústrias familiares rurais no município, das quais, seis estão em funcionamento. Das AFR em funcionamento, cinco são voltadas aos produtos de origem animal, como queijo, iogurte, rapadura e ambrosia, e uma é voltada a panificados, produzindo pães, cucas e bolachas. Nessas famílias, o trabalho das 
mulheres tem papel de destaque, seja na produção primária, na agroindustrialização dos produtos, ou na comercialização. Em dois casos, a agroindústria é responsabilidade somente de mulheres. Já nos outros três casos, mulheres e homens estão envolvidos na agroindústria, porém a agroindustrialização dos produtos costuma ser de responsabilidade das mulheres.

Com incentivos governamentais e apoio da EMATER, essas famílias de agricultores familiares de Santana do Livramento vêm implementando o processo de agroindustrialização da produção. A formalização da agroindústria é um processo recente, entretanto o processamento de alimentos produzidos pelas famílias é marcado pelo "saber fazer" reproduzido ao longo de várias gerações. Esse saber fazer e as receitas costumam ser passados de mães para filhas, assim como aponta Gazolla (2004).

Há políticas públicas que podem ser acessadas para iniciar ou fortalecer as agroindústrias familiares rurais. No âmbito da comercialização, dois programas governamentais se destacam pela potencialidade de fortalecimento dessas agroindústrias, possibilitando o acesso a mercados institucionais, por exemplo, o Programa Nacional de Alimentação Escolar (PNAE) e o Programa de Aquisição de Alimentos (PAA). Entretanto, efetivamente, em que medida acontece o acesso a esses programas? Qual a importância desses programas para o empoderamento das mulheres que atuam nas agroindústrias familiares rurais? Diante deste contexto, este artigo tem como objetivo estudar a participação das agroindústrias familiares rurais nos mercados institucionais do município de Santana do Livramento/RS, relacionando-a com o empoderamento das mulheres proprietárias dessas agroindústrias.

Justifica-se esta pesquisa pelo fato de que Santana do Livramento conta com a oferta de uma diversidade de produtos oriundos da agricultura familiar, entre produtos in natura e processados. Contudo, estes produtos, têm baixos índices de acesso aos mercados institucionais. Também, cabe destacar a importância das agroindústrias familiares para a agricultura familiar e para o desenvolvimento do território como um todo. Alguns estudos tratam da importância das agroindústrias familiares para as mulheres, como Boni (2006) e Sulzbacher e Neumann (2014), entretanto, não encontramos nenhum estudo que relacione agroindústrias familiares rurais, mercados institucionais e empoderamento das mulheres. Buscamos, através deste estudo, 
compreender melhor o tema proposto, bem como contribuir para o desenvolvimento territorial e para o empoderamento das mulheres do campo.

Essa pesquisa tem o caráter qualitativo. Utilizamos o método Estudo de caso, que, segundo Yin (2001, p. 27) representa "uma investigação empírica que investiga um fenômeno contemporâneo dentro de seu contexto da vida real, especialmente quando os limites entre o fenômeno e o contexto não estão claramente definidos". O caso estudado foi o empoderamento de mulheres proprietárias de AFR no município de Santana do Livramento/RS. Na verdade, trata-se de um estudo multicasos, abrangendo cinco mulheres.

As mulheres do campo proprietárias de AFR foram entrevistadas, com o apoio de um roteiro de questões, em janeiro de 2019. As entrevistas foram gravadas e, posteriormente, transcritas e sistematizadas por temas de interesse. Cada entrevistada assinou o Termo de Consentimento Livre e Esclarecido.

\section{Agroindústria familiar rural e sua importância}

As agroindústrias familiares rurais (AFR) são marcas das novas ruralidades no Brasil. Conforme Wesz Júnior, Trentin e Filippi (2009), as AFR estão relacionadas à busca pela diversificação produtiva, à revalorização de produtos tradicionais e à valorização de produtos com padrões de qualidade onde contam variáveis históricas, geográficas e culturais. Assim, os produtos das AFR são carregados de identidade territorial.

Nesse sentido, Quadros (2012, p.14), entende agroindústria familiar rural como

Uma atividade que assume uma forma e uma denominação moderna (tanto
pelo nome 'agroindústria' como pela exigência de infraestrutura específica),
mas seu conteúdo é essencialmente cultural e ligado ao tradicional
processamento de produtos agropecuários, sejam de origem animal ou
vegetal, sejam alimentos ou bebidas historicamente presentes no espaço rural
brasileiro.

A autora ressalta ainda que a administração e as tomadas de decisões competem aos membros da unidade familiar. Para a autora, "entende-se também, que a agroindústria familiar rural acaba constituindo um novo espaço e numa nova forma de empreendimento social e econômico, pois há agregação de valor e aumento de renda para os agricultores familiares" (QUADROS, 2012 p. 59-60). 
Ressaltando a importância do processamento da produção agrícola familiar, tanto para a comercialização como para a subsistência da família, Venturini (2011) cita o que chama de "agroindústria genuína", para qual sugere

\begin{abstract}
Onde o ato de processar é um saber fazer natural, original da família que não explora o processamento somente para fins comerciais, mas mercantiliza um produto da lógica de produção que, historicamente, é de subsistência, relacionada ao esforço de transformação de alimentos como forma de conservação e também uma forma de diversificar a dieta alimentar durante períodos de sazonalidade da produção (VENTURINI, 2011 p.5).
\end{abstract}

Para Quadros (2012), as agroindústrias tem capacidade de absorver o trabalho das mulheres e dos jovens, sendo de importância fundamental no vínculo familiar, evitando o êxodo rural. Outras vantagens são relacionadas às AFR por Wesz Júnior, Trentin e Filippi (2009): elevação/complementação da renda familiar no meio rural; redução da vulnerabilidade econômica dos agricultores familiares; diversificação e fomento das economias locais; descentralização da produção e das fontes de renda; adequação à estrutura fundiária existente; valorização das especificidades locais e preservação dos hábitos culturais; estímulo da proximidade nas relações comerciais (produtor-consumidor); geração de postos de trabalho no meio rural; redução do êxodo rural; estímulo ao cooperativismo e associativismo; preservação do meio ambiente e dos recursos naturais; e mudanças nas relações de gênero. Assim, a AFR gera trabalho e renda, contribuindo para a reprodução social e econômica destas famílias, além de resgatar questões culturais e contribuir para uma reconexão entre campo e cidade. Conforme Mior (2010), as AFR trazem importantes benefícios ao território. Entre eles, o autor cita as mudanças na organização das unidades de produção familiares, a organização da agricultura familiar, a diversificação econômica regional e o fortalecimento de sistemas agroecológicos de produção.

Os produtos das AFR guardam o caráter artesanal, sendo feitos em pequena escala. Assim, mesmo quando recriados, os produtos guardam a essência do saber fazer repassado entre as gerações no interior das famílias. Para Quadros (2012), esses produtos têm produção e beneficiamento artesanal e refletem hábitos de consumo locais, o que os tornam produtos diferenciados. Estes produtos são comercializados de diversas formas, como na venda direta em feiras livres e ambulantes, na terceirizada, através de outros comerciantes e nos mercados institucionais. Dessa forma, o incentivo 
governamental à criação e ao fortalecimento de AFR configura-se como uma forma importante de promoção do desenvolvimento territorial.

\section{Mercados institucionais e operacionalização}

Os mercados institucionais se configuram como uma importante forma de comercialização da produção gerada pelas agroindústrias. Entretanto, não obtém resultados homogêneos entre os diferentes municípios, o que leva a uma reflexão sobre a forma pela qual é realizada a sua operacionalização. Conforme Becker e Anjos (2015, p. 5), a "criação do Programa Fome Zero (PFZ) em 2003 representa o marco fundamental de políticas públicas de combate à fome e à insegurança alimentar, de onde deriva a criação dos mercados institucionais".

O Programa de Aquisição de Alimentos (PAA) tem por objetivo "[...] garantir o acesso aos alimentos em quantidade, qualidade e regularidade necessárias às populações em situação de insegurança alimentar e nutricional e promover a inclusão social no campo por meio do fortalecimento da agricultura familiar" (BRASIL, 2006 apud BECKER, ANJOS, 2015, p.6). O programa funciona a partir da aquisição de alimentos dos agricultores familiares. Esses alimentos são destinados às instituições beneficiárias que atendam pessoas que se encontram em situação de insegurança alimentar, a crianças e idosos (BECKER, ANJOS, 2015).

Já o Programa Nacional de Alimentação Escolar (PNAE), segue os princípios de universalização e gratuidade, e a sua reformulação mais recente ocorreu por meio da Lei $n^{\circ}$ 11.947/2009 (BECKER, ANJOS, 2015). Conforme esta lei, as escolas contempladas com repasses financeiros do Fundo Nacional de Desenvolvimento da Educação (FNDE), ficam obrigadas a adquirir da agricultura familiar e/ou de suas organizações, no mínimo 30\% do volume total de recursos correspondentes à compra de gêneros alimentícios (BECKER, ANJOS, 2015). No município de Santana do Livramento acontecem limitações na execução e fomento desta política, o que precisa ser trabalhado.

Esses programas proporcionam certa segurança aos (às) agricultores (as) quanto à comercialização de sua produção. Entretanto, podem tornar os atores sociais envolvidos dependentes do Estado e dessas formas de comercialização, conforme Becker, Anjos (2015, p. 08) 
Entre os agricultores familiares, os mercados institucionais de alimentos podem provocar dois efeitos claramente opostos entre si. Se por um lado, o PAA e o PNAE funcionam como indutores de processos de organização social e de estabelecimento de redes solidárias, de outra parte verifica-se um risco eminente de dependência dos produtores em relação ao Estado. Ou seja, os agricultores acabam destinando quase que a totalidade da produção para os mercados institucionais, deixando de acessar outros canais de comercialização.

Conforme a Lei 11.947/2009, o Programa Nacional de Alimentação Escolar (PNAE) tem por objetivo "contribuir para o crescimento e o desenvolvimento biopsicossocial, a aprendizagem, o rendimento escolar e a formação de hábitos alimentares saudáveis dos alunos, por meio de ações de educação alimentar e nutricional e da oferta de refeições que cubram as suas necessidades nutricionais durante o período letivo" (BRASIL, 2009, p. 02). Neste contexto, evidencia-se a importância destes alimentos serem saudáveis e serem ofertados ao longo do ano para os (as) estudantes.

Um grande volume de alimentos é necessário para suprir as demandas nutricionais em conformidade com a lei, conforme segue: os cardápios da alimentação escolar deverão ser elaborados pelo nutricionista responsável, com utilização de gêneros alimentícios básicos, respeitando-se as referências nutricionais, os hábitos alimentares, a cultura e a tradição alimentar da localidade, pautando-se na sustentabilidade e diversificação agrícola da região, na alimentação saudável e adequada. Esta mesma lei define também que, no mínimo, 30\% (trinta por cento) do total dos recursos financeiros repassados pelo FNDE, no âmbito do PNAE, deverão ser utilizados na aquisição de gêneros alimentícios diretamente da agricultura familiar e do empreendedor familiar rural ou de suas organizações, priorizando-se os assentamentos da reforma agrária, as comunidades tradicionais indígenas e comunidades quilombolas (BRASIL, 2009).

Porém, ainda há municípios onde esse percentual de compra mínima estabelecido pela lei está distante da realidade, como no caso de Santana do Livramento. Essa situação preocupa, pois o município poderia aplicar mais recursos na alimentação escolar, o que beneficiaria agricultores (as) familiares e que também garantiria maior qualidade para a alimentação dos (as) estudantes. Os públicos que podem ser atendidos pelo PNAE e pelo PAA perdem com problemas no funcionamento dos programas. Por outro lado, a situação dos (as) agricultores (as) também é difícil, já que estes (as) perdem sua produção e ficam mais vulneráveis diante desses problemas. 


\section{Agroindústria familiar rural e empoderamento das mulheres}

As lutas das mulheres do campo no Brasil tem sido discutidas em vários estudos realizados por autoras (es) como Costa e Marin (2018), Paulilo (2016) e Schaff (2001). Essas lutas não são no sentido de buscar superar os homens, mas sim de alcançar pautas como a valorização de seu trabalho, igualdade de direitos, participação nas tomadas de decisões, direito de viver sem sofrer violência de gênero, criação e fortalecimento de políticas públicas específicas etc. Entre os resultados dessas lutas, pode-se citar a conquista do reconhecimento da profissão agricultora, a aposentadoria como trabalhadora rural e o salário maternidade rural, conquistas que as camponesas do RS tiveram papel importante (SCHAFF, 2001).

Historicamente, no campesinato, assim como acontece em outros campos sociais, a mulher é vítima da dominação masculina (COSTA, MARIN, 2018). Os trabalhos desenvolvidos pelas camponesas têm sido desvalorizados e invisibilizados. As mulheres costumam se envolver na produção destinada à comercialização, juntamente com outros membros da família, além de assumirem outras jornadas de trabalho, como o cuidado de filhos, da casa, e produção para o autoconsumo, geralmente com pouca, ou nenhuma, participação dos homens da casa (PAULILO, 2016). O trabalho nas atividades percebidas como produtivas é, muitas vezes, considerado como 'ajuda' aos homens. Da mesma forma, os processos decisórios e o controle do dinheiro costumam ser centralizados na figura do marido ou pai, quando existe. Além disso, a violência de gênero no campesinato é intensa (COSTA, CAMARGO, NARVAZ, 2018). Dessa forma, historicamente essas situações contribuíram para prejudicar a autonomia das mulheres no campesinato.

Para qualquer ação realizada em prol do desenvolvimento rural é imprescindível discutir as questões de gênero. Conforme Boni (2006, p. 04),

Gênero não é sinônimo de mulheres. As relações de gênero se constroem com homens e mulheres e afeta toda a sociedade. A compreensão das desigualdades de gênero e de suas consequências no meio rural são imprescindíveis se quisermos construir um modelo de desenvolvimento rural que diminua as desigualdades.

Essa realidade de dominação masculina e de luta por transformação também acontece nas AFR. Quando falamos em desenvolvimento territorial gerado por elas, não podemos observar apenas aspectos financeiros e técnicos, já que as questões sociais são 
centrais. Nesse sentido, a pesquisa de Sulzbacher e Neumann (2014) trazem reflexões importantes sobre as AFR em relação ao desenvolvimento rural e à reprodução social. Conforme esse estudo, a AFR implica em aumento de trabalho, diminuição do lazer, alterações no convívio social na comunidade e na extinção de outras atividades que antes eram realizadas na propriedade, promovendo uma única fonte de renda e não a diversificação da unidade produtiva.

O estudo de Boni (2006) discute o aumento de trabalho e de responsabilidades das mulheres com a criação da AFR. Conforme a autora, na maior parte dos casos, elas acabam por não usufruir dos benefícios econômicos e de outros pontos positivos que a agroindústria traz, já que, muitas vezes, trabalham inclusive aos domingos para concluir o trabalho semanal.

Embora a grande maioria sinta esse peso, poucas mulheres têm a percepção de que é possível um modelo de agroindústria com caráter emancipatório, mas isso passa por um processo mais amplo dentro das estruturas familiares. Essa posição é sustentada, principalmente, por aquelas que participam dos Movimentos de Mulheres (BONI, 2006, p.21).

Essa citação é interessante porque Boni aponta um modelo de AFR emancipatório para a mulher. Nesse modelo, há a divisão dos trabalhos de forma justa entre mulheres e homens, possibilitando que as mulheres também possam ter tempo livre para lazer, para viver além do trabalho. Assim, entendemos que a AFR emancipatória é caraterizada pela divisão justa do trabalho na agroindústria, no cuidado da casa, dos (as) filhos (as) e de idosos (as) entre o homem e a mulher. Essa parece ser uma utopia quando confrontada com a realidade, mas é necessário caminhar em direção a ela. Nessa perspectiva, o conceito de empoderamento da mulher pode ser interessante.

Segundo Deere e Leon (2002) o empoderamento da mulher pode ser visto por outro ponto de vista que não o da forma de tirar poder do homem que vive em suas relações familiares o patriarcado, mas na forma em que a mulher libera o homem nos campos materiais e psicológico. Nesse caso, ela começa a dividir as responsabilidades que antes eram do homem liberando ele para outras emoções e situações. "Portanto, o empoderamento da mulher implica mudanças não apenas em suas próprias experiências, mas também nas de seus companheiros e familiares" (DEERE, LEON, 2002, p.55).

Segundo as autoras,

O empoderamento não é um processo linear com um começo bem definido e um final que seja o mesmo para todas as mulheres; é moldado para cada indivíduo ou grupo através de suas vidas, seus contextos e sua história, assim 
como ocorre de acordo com a posição de subordinação nos níveis pessoal, familiar, comunitário e nos níveis mais elevados (DEERE, LEON, 2002, p. $55)$.

Joice Berth trabalha empoderamento no sentido de empoderar grupos minoritários. Nessa perspectiva do feminismo negro, o termo empoderamento é um instrumento de emancipação política e social. Assim, empoderar não é tirar poder de um para dar a outro, invertendo os polos de opressão, mas sim "uma postura de enfrentamento à opressão para eliminação da situação injusta e equalização de existências em sociedade" (BERTH, 2018, p. 74).

\footnotetext{
Quando assumimos que estamos dando poder, em verdade, estamos falando na condução articulada de indivíduos e grupos por diversos estágios de autoafirmação, autovalorização, conhecimento e autoconhecimento de si mesmo e das suas mais variadas habilidades humanas, de sua história, principalmente, um entendimento sobre a sua condição social e política, e, por sua vez, um estado psicológico perceptivo do que se passa ao seu redor (BERTH, 2018, p. 64).
}

Essa perspectiva de empoderamento de Berth é interessante, pois supera críticas feitas anteriormente ao conceito empoderamento. Cabe mencionar que nessa linha se entende que não é possível empoderar outra pessoa, já que empoderamento é um processo. "Empoderamos a nós mesmos e amparamos outros indivíduos em seus processos, conscientes de que a conclusão só se dará pela simbiose do processo individual com o coletivo" (BERTH, 2018, p. 1294).

$\mathrm{O}$ conceito de empoderamento utilizado nesse artigo refere-se a perspectiva de Berth (2018) que tem como base o feminismo negro. Assim, entendemos que o empoderamento da mulher é um processo que envolve a sua tomada de consciência e o seu comprometimento pela transformação da sua vida e da sociedade, em busca de equidade de gênero.

\section{Agroindústria familiar rural no contexto de Santana do Livramento}

Atualmente, em Santana do Livramento, existem nove agroindústrias familiares rurais formalizadas. Porém, algumas dessas se encontram paradas. Também há uma lista de famílias interessadas na atividade de processamento, nas mais diversas categorias, aguardando algum recurso via projetos governamentais ou de instituições privadas para implementá-las. Atualmente, três AFR se encontram em processo de regularização no 
município. Todas as agroindústrias citadas recebem a assistência da Emater, e as de origem animal também contam com um (a) responsável técnico (a).

A primeira agroindústria familiar do município foi a da Sra. Zelda, a qual atua na atividade há 30 anos, estando formalizada desde 2009. A propriedade onde ela vive com as duas filhas, de 8 hectares, localiza-se a $11 \mathrm{~km}$ da sede do município. A comercialização da sua produção já é realizada há 25 anos em uma rede de supermercados da cidade, sendo apenas uma pequena parte comercializada direto ao (à) consumidor (a), costumeiramente na própria residência. Desde que se casou, Zelda sempre trabalhou na bovinocultura de leite, fazendo queijos para o autoconsumo e comercialização, além de cuidar da casa e das filhas.

O processo dessa agroindústria era todo artesanal, realizado dentro da cozinha. Em 2000 foram solicitadas algumas alterações a fim de melhorar o procedimento e a segurança alimentar. Em 2009, com as filhas ainda moças, teve de encarar a perda de seu esposo, o qual era responsável pela parte burocrática e pela venda dos produtos. Agora viúva, precisou encarar as dificuldades e superar todos os desafios para continuar a sua produção e obter dessa atividade o sustento da família. A fiscalização foi um dos maiores desafios enfrentados para permanecer com o processamento de queijos, pois agora não podia mais continuar utilizando o nome de seu marido, e assim, para obter uma nova licença precisou se adequar às novas leis vigentes.

Ao mesmo tempo em que ocorreu esse processo de mudanças, a filha mais velha ingressou na Universidade Estadual do Rio Grande do Sul (UERGS), no curso de Tecnologia em Agroindústria. Durante as atividades do curso, foi elaborado todo o projeto para a execução da agroindústria de processamento de queijos. A aproximação com os professores e os conteúdos de aula contribuiu de forma significativa para que Zelda viesse aceitar o desafio e desse início à formalização. Porém, houve uma exigência que ainda não foi completamente aceita: o princípio de qualidade e sabor diferenciado do seu produto exige que o queijo deva ser maturado sem refrigeração, conforme ela mesma explica: "Como eu digo, o meu queijo eu não coloco em geladeira, porque o meu queijo é secado como o queijo da vovó, é maturado. [...] O meu queijo é considerado como queijo caseiro mesmo, como antigamente" (Entrevistada Zelda, 2019). 
A construção da sua agroindústria se deu através da renda obtida com a venda de 16 animais, pois ela não acessou nenhum recurso governamental no primeiro momento. Após algum tempo, Zelda conseguiu acesso a um recurso através do Orçamento Participativo, juntamente com outras quatro AFR. Com este recurso, providenciou a construção do galpão para realizar a ordenha e a compra de mais alguns animais. As filhas de Zelda trabalham fora da propriedade, o que faz com que ela assuma sozinha todo o trabalho com o gado de leite, a produção e a comercialização dos queijos, além do cuidado da casa.

Outra agroindústria de laticínios é a da Cláudia, em propriedade arrendada a uma distância de 6,5 km da sede do município. Cláudia, juntamente com seu marido, atua na bovinocultura de leite há 25 anos, no processamento de queijos e derivados de leite há 4 anos. A família, o casal e um filho menor de idade, residem na propriedade. $\mathrm{O}$ esposo de Cláudia fez o curso para a fabricação de queijos, via Emater, porém ao retornar se deparou com a falta de recursos para fazer a agroindústria. Quando surgiu a possibilidade de utilizar recursos do Orçamento Participativo foi dado o início para a realização do sonho do casal.

A construção da agroindústria foi com recurso próprio. Através da verba do Orçamento Participativo, foram adquiridos os equipamentos e as máquinas e. $\mathrm{O}$ trabalho é realizado por Cláudia e por seu esposo. A comercialização é feita através da venda direta, em uma rede de supermercado local, em pequenos comércios e para os mercados institucionais (PAA e PNAE). O casal hoje enfrenta problemas como falta de mão de obra, o que exige muito tempo e esforço deles, conforme o relato

Surgiu de um sonho que meu marido tinha. Ele sonhava em além de ser
produtor de leite, ser produtor de queijo porque ele sonhava em agregar valor
ao litro do leite. Só que ele não sabia que com esse sonho vinha junto muito
mais trabalho [...] Eu comecei a sonhar o sonho dele, e hoje eu trabalharia só
com queijo e não com o leite, não te digo que deixaria $100 \%$ de produzir
leite, mas eu diminuiria o número de animais, e numa eventual falta de leite
eu compraria leite né, pra industrializar, coisa que ele não aceita. Isso ele não
entende como bom, e eu hoje trabalharia com o queijo e diminuiria o número
de animais porque tira muito tempo da gente. Mas ele acha impossível que
não seja o leite dele, que ele produz pra fazer o queijo. [...] É que ele sabe o
leite que tem ali (Entrevistada Cláudia, 2019).

Na fala de Cláudia podemos perceber a importância dada para a qualidade e a preocupação com a segurança alimentar dos consumidores, o que é um diferencial dos agricultores familiares. Também podemos perceber que as visões dela e do marido são distintas em relação a decisões importantes na gestão da agroindústria, como a origem 
da matéria prima. $\mathrm{O}$ excesso de trabalho faz com que ela queira diminuir a produção do leite, questão com a qual o marido não concorda, e por isso não é colocada em prática. Entendemos que o somatório de todas as atividades desenvolvidas juntamente com o marido, com o cuidado da casa e do filho, preponderantemente desenvolvidos pela mulher, segunda e terceira jornadas de trabalho no sentido de Paulilo (2016), provocam a sobrecarga de trabalho da qual Cláudia reclama.

A agroindústria de Liliane, também de laticínios, está localizada a $17 \mathrm{~km}$ da sede do município. Moram na mesma propriedade seus pais, dois irmãos e as duas cunhadas, além da família que é composta por ela, o marido e duas filhas pequenas. Dentro da família há uma clara organização de cada pessoa entre as atividades da agroindústria, bovinocultura de leite e produção de hortaliças. Além deles, contrata-se um trabalhador externo. Liliane é a principal responsável pelo trabalho na agroindústria e pela sua administração, além de participar da comercialização dos produtos com sua mãe e se dedicar ao cuidado das crianças e da casa. A agroindústria foi construída inicialmente com recurso do FEAPER (Fundo Estadual de Apoio ao Desenvolvimento dos Pequenos Estabelecimentos Rurais). A comercialização de queijos, iogurte, manteiga e ambrosia é feita em pequenos comércios, direto a consumidores em feiras e para os mercados institucionais. A propriedade produz leite há 15 anos e há 3 anos iniciou o processamento.

A história dessa agroindústria inicia no momento em que o pai de Liliane comprou algumas vacas de raça cruzada leiteira e ela então começou a realizar a ordenha para não perder o leite. Liliane então aprendeu a fazer os queijos com conhecidas e começou a produção. Seu pai já trabalhava com a venda das hortaliças que a família produzia, e também vendia os queijos e o leite direto aos consumidores. Porém, com a pressão sobre a venda informal de leite e derivados, ela decidiu encerrar o processamento e passou a vender o leite para uma empresa que fazia a coleta na propriedade. Conforme conta em seu relato

Sobrava aquele monte de leite e eu comecei a fazer queijo. Perguntei pra umas amigas da mãe como é que fazia, e comecei a fazer. Daí a gente não consumia e o pai começou a vender e eu comecei a gostar do dinheiro né. [...] Eu fazia queijo, eu tinha uns 14 anos, agora estou com 36, eu fazia queijo assim em casa, foi quando surgiu essa lei que não podia vender leite na rua. Não podia vender queijo, essas coisas assim, daí eu parei de fazer queijo e vender leite na rua (Entrevistada Liliane, 2019). 
A AFR de Clarice é voltada à produção de panificados, como cucas, pães e biscoitos. Clarice atua há 17 anos nesse ramo, estando formalizada a sete meses. A distância da agroindústria é de $50 \mathrm{~km}$ da sede do município. A sua casa e a agroindústria estão dentro da propriedade de seus pais, um lote de terra de um projeto de reforma agrária fundado em 1998. Clarice é a responsável pela agroindústria, que também conta com o trabalho da mãe na produção, da irmã na comercialização, esporadicamente do irmão adolescente, e de uma vizinha. O pai e o marido de Clarice não atuam na agroindústria.

A agroindústria teve início devido à necessidade financeira pela qual passava a família na chegada ao lote. Dessa forma, já em 2001, a receita da cuca recheada, um saber fazer passado ao longo das gerações, no caso da avó para filha e agora para as netas, foi a forma que encontraram para melhorar a renda da propriedade.

Sempre de forma caseira e artesanal, com equipamentos domésticos e não industriais, a atividade gerou trabalho e renda para as três mulheres da casa, e ainda para algumas vizinhas que eram chamadas para ajudar. Com o egresso da irmã em 2012 no curso de Desenvolvimento Rural e Gestão Agroindustrial, onde conheceu as agroindústrias familiares, surgiu a ideia que levou para Clarice. A aceitação da formalização da produção foi difícil no início, pois Clarice não gostou da ideia. Porém, aos poucos, com a irmã se disponibilizando a ajudar em toda parte burocrática, e mostrando as possibilidades de ampliar o mercado, ela foi aceitando. Após um tempo, com o auxílio da Emater, conseguiram acessar o FEAPER para o início da obra, o restante foi construído com recursos próprios. Após um período de seis anos após o início da construção até a sua conclusão, conseguiram inaugurar a agroindústria, o que mostra a dificuldade para acessar recursos financeiros.

A comercialização é feita diretamente aos (às) consumidores (as), nas feiras locais, por outras feirantes que revendem os produtos e recentemente na loja de produtos coloniais da irmã. O primeiro medo de Clarice foi sobre o risco de perder o sabor caseiro tradicional dos seus produtos. Pois, em muitos anos trabalhando com matéria prima originada da produção da propriedade e da família, sabia que teria de cumprir com as exigências impostas pela legislação. Essas exigências acabam se contradizendo no que se refere ao processamento da produção agrícola, já que passam a exigir que os insumos sejam todos de procedência industrial, e não permitem mais o uso 
de produtos produzidos na propriedade, como é o caso do ovo caipira, do leite in natura, da nata e da manteiga. Conforme ela relata,

\begin{abstract}
Acho ruim é a legislação do nosso país que obriga que eu use tudo industrializado que eu não posso usar os meus produtos, porque quando eu trabalhava na informalidade eu podia usar os nossos ovos, a nossa nata, nossa manteiga. E hoje não, hoje tudo tem que ser industrializado. Então eu tenho muito medo muitas vezes de sair do meu colonial, porque a única coisa que eu bati muito de frente foi que eu não queria deixar de vender o meu caseiro, o colonial, porque padaria tem em cada esquina na cidade. Então, se é para mim vender um produto igual dos outros, eu não trabalharia, porque o que me satisfaz é vender um produto colonial, um produto diferenciado. Porque eu gosto que as pessoas comam e digam assim 'oh, isso lembra minha vó, isso lembra minha mãe, eu só comia esse pão que lá a minha madrinha fazia' [...]. Então Isso pra mim é muito gratificante e por mais que fique doze ou quatorze horas dentro da agroindústria, aquilo me satisfaz em saber que eu produzo a quantidade de biscoito que eu faço na semana, e saber que aquilo tem consumo, que as pessoas não compram obrigadas, elas vem atrás daquele produto porque elas gostam (Entrevistada Clarice, 2019).
\end{abstract}

A preocupação com a qualidade do produto é recorrente entre as entrevistadas, aparecendo agora nas palavras de Clarice. Assim como Zelda, ela não quer perder a originalidade e o teor colonial de seus produtos. É interessante que Clarice mencionou que o gosto da cuca precisa lembrar o 'da vovó", exatamente como Zelda se referiu ao gosto do queijo. Para elas, é importante guardar o saber fazer repassado pelas mulheres na família ao longo das gerações, protegendo-o diante das imposições da legislação. Dessa forma, elas são defensoras da agroindústria genuína conforme o conceito de Venturini (2011).

A agroindústria de Mirta, também de laticínios, atua no processamento de doce de leite, ambrosia e rapaduras, estando localizada a $19 \mathrm{~km}$ da sede do município. Mirta trabalha com agroindústria já há 10 anos, sendo que há quatro anos é formalizada. Ela e seu marido tem um filho menor de idade que mora com eles. Ela costuma dedicar muitas horas do dia para trabalhar com bovinocultura de leite, realizar as atividades da agroindústria, preparar e fazer feira. Além disso, costuma assumir praticamente todas as atividades domésticas.

Mirta iniciou a atividade com a fabricação de queijos que vendia na feira, e depois incorporou a comercialização de rapaduras elaboradas a partir de receita da família. A família trabalha também com hortaliças, as quais comercializa nas feiras e nos mercados institucionais. Os processados são vendidos direto aos consumidores nas feiras e em alguns pequenos comércios. Após ser incentivada a formalização pela 
Emater, Mirta conseguiu acessar recurso do FEAPER, porém precisou concluir a obra com recursos próprios, o que causou dificuldades e demora.

\section{O acesso aos mercados institucionais das AFR estudadas}

A venda para os mercados institucionais não ocorre em duas das cinco agroindústrias estudadas. Em um dos casos por ter pouca produção e no outro por sua recente formalização. O PAA tem sido realizado através de chamadas públicas destinadas aos quarteis do município, que tem bons resultados na sua execução. Esse programa tem demanda todos os anos, e realiza a compra e os pagamentos de forma regular. O PNAE é realizado nas escolas municipais e estaduais do município. Esse programa apresenta várias dificuldades na sua operacionalização, desde a elaboração do edital até o pagamento dos produtos.

Durante as entrevistas buscamos compreender os pontos positivos e negativos da execução destes programas, assim como, os entraves que prejudicam a sua eficácia em todo o processo. Algumas mulheres se demonstraram insatisfeitas quanto ao funcionamento dos mercados institucionais no município, porém todas reconheceram a importância dessa forma de comercialização.

Cláudia reclama da burocracia da Prefeitura Municipal:

Pra nós é ótimo, no começo meu marido falava em comercializar só nesses mercados, ele não tinha a ideia. Mas claro, a gente pensava que isso era uma coisa que engrenava e funcionava bem e que não parava, mas na verdade não é dessa maneira. Tem seus excessos burocráticos, as suas dificuldades e quando nós vendíamos, por exemplo, pra prefeitura que é através do PNAE (Eu confundo eles, os programas), 'as vezes tinha suas dificuldades pra cobrar e daí tinha que fazer o empenho. E o empenho era eu que pegava na Secretaria da Educação e levava na Secretaria da Fazenda, mas nunca deixei de cobrar, mas sempre tinha que ter um jeitinho. E é um valor bom, a gente entrega e recebe, pra nós é ótimo (Entrevistada Cláudia, 2019).

A questão da demora e da burocracia na Prefeitura também se repete na fala de Liliane, porém por se tratar de uma venda garantida, ela também se demostra satisfeita. Comenta também a importância destes para um planejamento interno, já que ao saber a demanda ela pode produzir e ter a venda garantida. Com a entrada dessa renda, também consegue planejar melhor os investimentos da agroindústria, como segue:

Isso aí é muito bom, que é bom porque é uma venda garantida uma venda certa e que tu é só entregar, produzir e entregar. Tá, a prefeitura demora um pouquinho pra pagar, essa coisa, mas nunca ninguém ficou me devendo, sempre me pagou. Isso assim oh, é uma venda que eu tenho. Por exemplo assim, de um ano para o outro, hoje eu já sei mais ou menos o que eu tenho 
vendido pra esse ano sabe, então quer dizer que chega ser uns $30 \%$ da venda da agroindústria, claro que até se concretizar a gente não sabe se vai se concretizar. Porque pra prefeitura mesmo diminuiu bastante esse ano então a gente não sabe quanto por cento a gente vai ter. No ano passado a gente não vendeu porque compraram no último mês e aí no fim, até a gente chegava nas escolas e diziam: 'queijo de novo, o que a gente vai fazer com tanto queijo?' Por causa que o que era pra ser comprado em três meses ou no ano inteiro, foi comprado tudo, eles colocaram o que deu no último mês, porque foi só no último mês que a gente entregou, foi novembro e dezembro, mas dezembro foi bem pouquinho porque dia 18 já termina, eu fui até o dia 18 que fiz a minha última entrega (Entrevistada Liliane, 2019).

A problemática da demora desde a construção do edital até a entrega dos produtos nas escolas municipais, afeta não somente as agricultoras, mas também todos dentro das escolas. Dessa forma, a segurança nutricional acaba não se concretizando e as responsáveis pela alimentação precisam atender o cardápio com a falta destes itens. Sendo que, em outro período, há um excesso destes produtos e que acabam sem saber o que fazer com estes. Dessa forma, acaba por não atender o objetivo da lei que determina a aquisição de alimentos saudáveis que garantam a necessidade nutricional diária.

Outra insatisfação é apresentada por Mirta. Ela apenas realizou uma venda da agroindústria através do PAA, isso porque trabalha com doces e estes não são aceitos pelos nutricionistas devido ao açúcar. Outra questão é que os produtos que ela trabalha foram solicitados no PAA com valores abaixo do custo de produção. Já o seu esposo consegue comercializar a produção de hortaliças nesses mercados, mas enfrenta perdas de produção devido às falhas na execução do programa.

Assim, Mirta lamenta ter sido motivada pelos extensionistas a construir uma agroindústria e formalizar a produção, sendo que não houve aumento da comercialização, porém gerou contas fixas e de valor alto, como o pagamento da responsável técnica e outras taxas que são mensais.

Foi bom pra esse programa aí, mas foi o único bom que se vendeu bem. Teria que ter mais. Tu trabalha motivada, tu sabe, como ele diz (o marido), eu entrava às vezes seis da manhã e as vezes era meia noite e eu ainda estava ali oh, de fazer 10 panelas, tu sabe o que é fazer 10 panelas? Tudo no dia, tudo no braço. Mas compensou porque o dinheiro que peguei mesmo todo dele foi para as vacas que comprei, então como eu digo é dinheiro investido [...]. Até eles me conversaram né (refere-se a promessa de comercialização para os mercados institucionais), porque eu preferia trabalhar informalmente porque pelo lucro eu ganhava bem mais. Mas daí porque iam vender para as escolas e iam vender, pra isso deram aquela ajuda (se referindo ao FEAPER) e na verdade não (Entrevistada Mirta, 2019). 
A penosidade do trabalho aparece novamente aqui, como um fator limitante para aumentar a produção, já que se trata de processamento artesanal. Mirta relata também o fato da sua insegurança em investir em equipamentos industriais, como panelas, pelo fato de não ter mercado certo. Por mais que poderia comercializar a sua produção em mercados locais, ela se sente insegura e isso limita o desenvolvimento da sua atividade. Se ela pudesse comercializar para os programas, teria mais facilidade e garantia de pagamento para o investimento.

A agroindústria de Clarice ainda não realiza a comercialização através dos mercados institucionais, por ter sido recentemente inaugurada e sendo assim, ainda não foi solicitado por nenhuma organização. É preciso que estas saibam que estes produtos estão sendo ofertados e portando possam vir a acrescentar em suas demandas, o que ainda não foi passado para todas. No entanto, Clarice traz em sua fala as dificuldades que enfrenta atualmente por não ter recursos financeiros para compra de máquinas e equipamentos industriais, devido ao alto custo destes, e por isso, a produção ainda é realizada totalmente de forma artesanal, o que traz consequências a sua saúde, devido à penosidade desta atividade.

Clarice também ressalta a segurança financeira para esses investimentos maiores através da comercialização pelos mercados institucionais. Ela avalia como muito importantes estes programas, já que conta com eles para fazer novos investimentos. Foi com essa intenção que aceitou a formalização da AFR. Conforme seu relato:

\begin{abstract}
Mesmo isso não tendo se concretizado ainda, é um sonho, porque por mais que hoje a gente venda bem, eu tenho que produzir e vender. Se eu conseguisse, agora vou usar de exemplo a chamada pública, isso seria uma renda a mais do que eu trabalho hoje e uma renda fixa entendeu. Então poderia me levar a conseguir uma amassadeira, o meu carro próprio. Porque é uma renda a mais, é mais seguro, com certeza eu daria conta (Entrevistada Clarice, 2019).
\end{abstract}

A satisfação com os mercados institucionais ocorre através do aumento da renda e com a garantia de venda certa. As AFR conseguiram investir melhor o dinheiro e se planejar com a demanda destes mercados. Também cabe frisar que a formalização de algumas AFR se deu para acessar os mercados institucionais, embora as falhas na operacionalização no município frustrem as expectativas das agricultoras.

Em todas as entrevistas são relatadas as falhas que ainda ocorrem com frequência, principalmente dentro do PNAE, no município. As famílias se organizaram 
para a comercialização em 2018, e muitas perderam produção, principalmente vegetais, pela demora na compra. Percebe-se que não há uma regularidade na abertura de editais e também a quantidade adquirida via PNAE é inferior à qual é determinada em lei, mínimo de 30\%. Isso provavelmente ocorra devido aos atores envolvidos pela execução desta política não estarem capacitados adequadamente para a sua execução, o que afeta diretamente os (as) agricultores(as) e os (as) beneficiários (as) dos programas, como segue no desabafo de uma das entrevistadas:

É não ter uma sequência assim, é ter intervalos e intervalos grandes. Se nos
conseguisse uma forma de comercializar mais seguido que não tivesse tanto
espaço pra nós seria melhor. [...] Olha na questão das escolas, eu vejo pelas
reuniões, aí é sei lá se falta boa vontade, se as pessoas não têm aí eu não sei
nem te explicar, porque às vezes a gente vê coisas que nem dá pra falar [...].
Será que é mal administrado? Acho que uma má administração, pessoas que
não tem uma capacidade pra organizar isso tudo ali dentro, porque eu acho
que isso tem que ter organização, tem que ter cabeças pensantes, inteligentes
que olhem para quem produz com outros olhos, pra fazer a engrenagem
andar. A gente acompanha reportagens na televisão que aí que gente fica de
boca aberta. Produtores satisfeitos com PNAE, com PAA. E aí a gente às
vezes comenta aqui assim: 'oh, por que que aqui não funciona? Onde está o
erro, quem que consegue apontar o erro, é falta de organização?' Eu não
entendo, sinceramente eu não consigo entender (Fala de uma das
Entrevistadas, 2019).

A demora e a falta de pedidos coerentes com a oferta de produtos dos (as) agricultores (as) tem sido um dos maiores entraves da comercialização das agroindústrias familiares através dos mercados institucionais no município. As pessoas criaram expectativas em torno destes programas para a formalização de suas agroindústrias, que sempre requerem investimentos altos. No entanto, essas pessoas acompanham o sucesso e a eficiência da execução destes programas em outros municípios. Fica aí o questionamento sobre o porquê de em Santana do Livramento/RS, após quase duas décadas de existência destes programas, ainda ocorrerem tantas falhas. Apesar de todas as entrevistadas estarem vendendo, ou terem a intenção de vender para os mercados institucionais, não ocorre aqui a venda exclusiva para este programa. Todas buscam, além da venda direta, também os outros comércios locais para realizar a venda da sua produção, diversificando as suas possibilidades.

Em Santana do Livramento, os maiores problemas estão relacionados ao PNAE. Percebe-se que há uma falta de diálogo entre os atores envolvidos na execução do programa, o que contribui para ocorrerem os atrasos na elaboração dos editais, além de falhas internas dos setores da prefeitura que são responsáveis desde a elaboração até 
a publicação de editais e efetivação da compra. Como não foram realizadas entrevistas com esses atores, não podemos identificar aqui quais as explicações que são dadas para esses problemas. Os depoimentos das agricultoras envolvidas com os mercados institucionais nos dão pistas sobre os problemas que acontecem no município. O PAA tem contribuído de forma significativa para as AFR do município, porém ainda são enfrentados alguns problemas quanto ao período de solicitação e de entregas dos produtos. Já com relação do PNAE, os problemas de operacionalização são mais graves.

Para atingir o objetivo dos programas, o município precisa oportunizar capacitação para os profissionais que trabalham na operacionalização do PAA e do PNAE. Dessa forma, e com a construção conjunta de agentes relacionados a esses programas, pode-se potencializar o desenvolvimento do município e do território.

\section{AFR, mercados institucionais e empoderamento de mulheres em Santana do Livramento}

Como visto anteriormente, a relação entre as AFR e os mercados institucionais ainda não acontece da forma adequada no município. Sabe-se que o município tem potencial para ampliar e diversificar a oferta de produtos da agricultura familiar e das AFR locais aos mercados institucionais, assim como necessita de maior geração de trabalho e renda para estimular a permanência no campo. As AFR possuem potencial para contribuir bem mais do que contribuem nesse sentido.

Diante dos entraves para alcançar a eficácia dos programas vistos anteriormente, ao questionar as agricultoras sobre a satisfação de terem optado pela formalização das agroindústrias, obtivemos diferentes respostas. No caso de Zelda, ela se demonstra satisfeita, pois sempre quis um lugar específico para a fabricação do queijo, como ela relata

Até me emociono só de pensar, porque só Deus sabe e eu sei que sempre tive esse pensamento desde que casei, é pra não fazer dentro de casa e outra que também foi uma grande benção a agroindústria foi por que ela descobriu a doença da filha (alérgica a ácido láctico) (Entrevista de Zelda, 2019).

Durante as entrevistas, foi relatada uma melhora na aceitação e na credibilidade dos consumidores, por estarem consumindo produtos com maior segurança alimentar. A valorização pessoal e o fortalecimento da autoestima são trazidos aqui pelas 
entrevistadas como um importante fator de satisfação, recompensando o árduo trabalho que realizam no interior de suas propriedades. As mudanças que ocorreram com a formalização da AFR são relatadas por Cláudia:

\begin{abstract}
Olha, a conquista da autoestima, recuperou a autoestima que estava perdida, porque antes de ter a produção de queijo, a gente passou por uma situação crítica financeira muito grave [...] A engrenagem foi se ajustando e a gente conseguiu o equilíbrio financeiro e isso foi importantíssimo. E o que tem de maior alegria pra mim, é quando eu consigo entregar o queijo, e o produto, entregar os queijos para o consumidor, ali no supermercado, por exemplo. Eu peso e sou a promotora de vendas do meu queijo também, então estou expondo ele lá e pesando. Naquele momento assim oh, toda vez que eu faço a entrega, eu me sinto realizada, porque é o encerramento do ciclo que começa na propriedade. Então é isso que eu posso te dizer do queijo, ele melhorou a nossa renda, melhorou nossa autoestima, me trouxe mais atividade, me trouxe mais trabalho, mas também me realizou (Entrevistada Cláudia, 2019).
\end{abstract}

Nessa fala percebemos implicações positivas das AFR, mas também aparecem implicações negativas. Em todas as entrevistas são relatadas as dificuldades quanto ao aumento de trabalho e a falta de mão de obra. Neste caso, apesar do aumento do trabalho, ela se sente realizada. As entrevistadas estão inseridas dentro das agroindústrias e estas proporcionam a sua renda e apesar das dificuldades todas elas fazem planos para o futuro de permanência nessa atividade. Nas cinco AFR estudadas, a mulher é responsável pela produção e comercialização, assim como é ela que toma as decisões e efetua a gestão. Apenas em uma destas o marido atua diretamente na produção, mas a agricultora está ali envolvida nas demais atividades que envolvem a agroindústria e o trabalho de toda a propriedade.

Podemos afirmar que as agroindústrias contribuíram para o empoderamento de todas as mulheres entrevistadas. Clarice avalia como um importante ponto positivo da AFR a possibilidade de poder trabalhar em casa, com autonomia, gerando a sua renda. "A minha independência, financeiramente eu resolvo a minha vida, não preciso pedir nada" (Entrevistada Clarice, 2019). Nesse caso, mãe e filhas se empoderaram a partir do momento em que decidiram superar as dificuldades e buscar uma nova forma de sustento para a família. A imagem abaixo mostra a realização da mãe por trabalhar ao lado da filha na agroindústria. 
Figura 01 - Entrevistada Clarice e sua mãe trabalhando na Agroindústria Lutke Brot

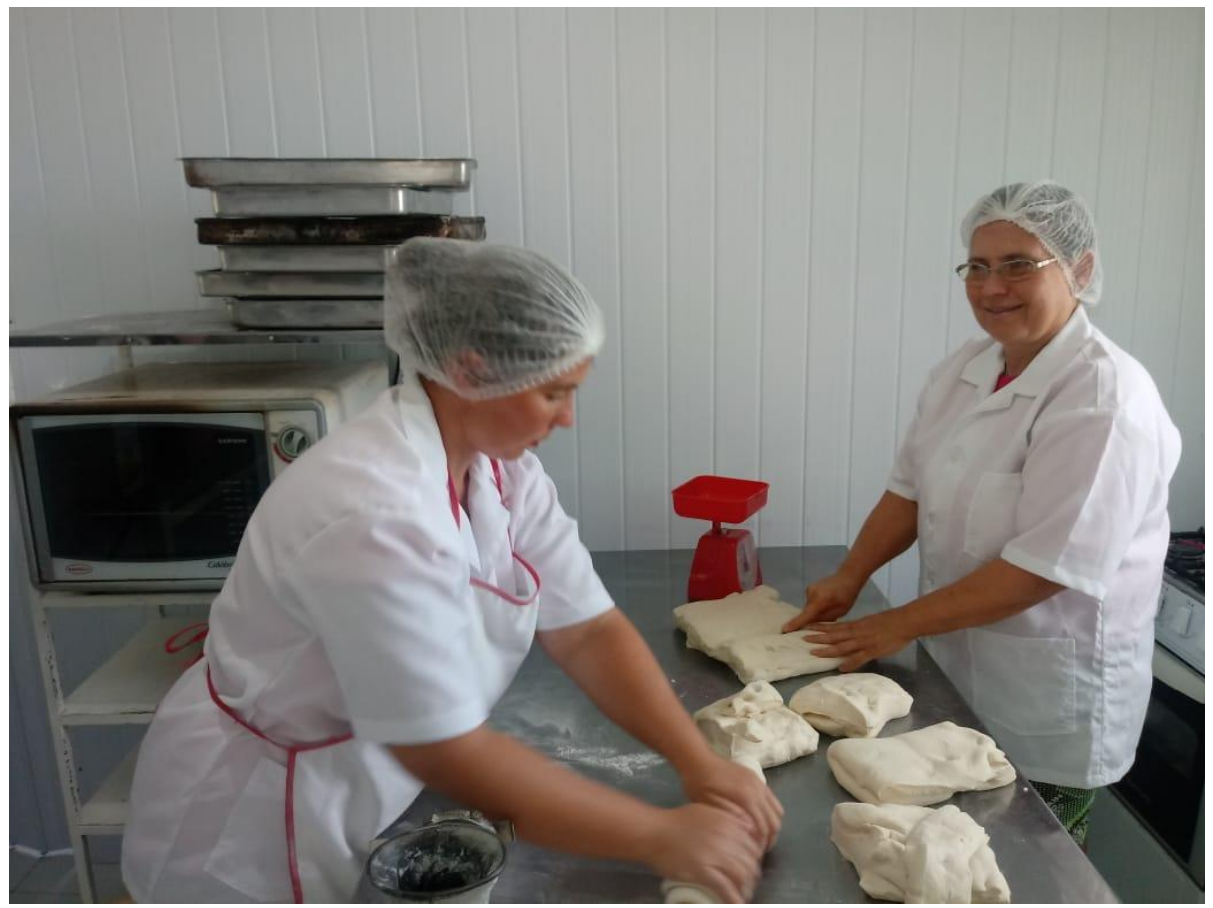

Fonte: Arquivo de Vanessa Lutke, 2019.

Nesse contexto, o acesso aos mercados institucionais tem potencial para fortalecer o processo de empoderamento das mulheres envolvidas em AFR. Os mercados institucionais possibilitam o aumento das vendas e a certeza da comercialização da produção, possibilitando às mulheres planejarem ações futuras com maior tranquilidade e aumentarem a renda e autonomia. Dessa forma, entendemos que garantir a participação das AFR nos mercados institucionais também significa favorecer o processo de empoderamento das proprietárias dessas agroindústrias.

Por exemplo, Clarice sonha com a comercialização através dos mercados institucionais, o que irá aumentar a demanda pelos produtos da AFR e contribuir com o empoderamento seu, da sua mãe e da vizinha que lhe auxilia na produção. Conforme sua fala:

Porque se eu entrar, vamos supor num mercado desses, eu não sei ainda como é a forma de pagamento, se é de mês em mês ou o que. Eu poderia chamar a vizinha todos os dias, eu teria condições de pagar uma diária pra ela de segunda a quinta ou no sábado também [...]. Eu teria como pagar ela, então eu poderia reduzir eu meu horário de trabalho e ela passaria a ganhar a mais que é o sonho dela, porque é só o que ela fala no momento, ela tá sonhando que isso se concretizar (Entrevistada Clarice, 2019). 
A vizinha de Clarice casou-se muito nova e tem uma filha. Com a possibilidade de auxiliar na agroindústria, enfrentou os desafios e superou as dificuldades. Neste período em que trabalha ali, já adquiriu através do seu trabalho, um pequeno veículo e aprendeu a dirigir para se deslocar da casa até o trabalho, o que foi uma grande superação para ela. Tornando-se independente, agora também tem a decisão sobre suas compras e seus planejamentos. Como ela não foi entrevistada diretamente, mas conhecemos a sua história, trouxemos ela para o texto através do relato de Clarice que trabalha com ela diariamente: "Ela passa dizendo que toda a mudança na vida dela é culpa minha, rsrsrs". Fica claro que uma agroindústria tem o potencial de transformar a vida de várias mulheres, como aconteceu com a Lutke Brot.

No caso de Zelda, ela já atuava na produção da sua agroindústria, porém com a perda do marido teve que se reorganizar para sustentar a ela e as duas filhas. Com muita persistência, formalizou a sua produção e conta com a renda desta atividade até o momento, e pretende continuar até a sua aposentadoria. Zelda venceu grandes desafios, se tornou referência em formalização de AFR e mostrou o potencial da mulher na agroindústria em vários lugares do país, do que ela se orgulha.

Já Liliane se considerava empoderada mesmo antes da formalização da agroindústria, pois ela começou a ter sua própria renda e a construir o seu negócio através da venda do leite e seus derivados ainda na informalidade, quando moça. Fazer queijo foi a forma encontrada por ela para construir a sua autonomia financeira.

Embora esses casos mostrem que as AFR e o acesso aos mercados institucionais contribuem com o empoderamento das mulheres envolvidas com elas, é necessário atentar para a sobrecarga de trabalho gerada para as mulheres pela agroindústria. As entrevistas confirmaram nesse contexto a afirmação de Boni (2006) de que a AFR gera o aumento do trabalho e de responsabilidades das mulheres. Nesse sentido, uma AFR que gera doze a catorze horas de trabalho por dia para a mulher, como relata uma entrevistada, pode ser efetivamente entendida como promotora de empoderamento? As melhoras na autonomia financeira e na autoestima relatadas pelas entrevistadas se sustentarão nessas condições de trabalho?

Em quatro dos cinco casos estudados, o trabalho na agroindústria é atribuição das mulheres. Assim, a agroindustrialização de alimentos é percebida como uma extensão da cozinha da casa. Como costuma acontecer na cozinha da casa, o trabalho na 
agroindústria é percebido como "coisa de mulher". Dessa forma, as mulheres somam o trabalho da agroindústria e o cuidado da casa e dos filhos (que costumam ser atribuídos a elas) com o trabalho em outras atividades agropecuárias da propriedade e a comercialização (com o companheiro, quando tem). Como resultado, todas as entrevistadas tem uma jornada exaustiva de trabalho que deixa pouco tempo para o lazer e o cuidado de si mesmas.

É necessário mudar essa situação apostando na criação e no fortalecimento de agroindústrias familiares de caráter emancipatório, para usar a denominação de Boni (2006). Entendemos que a AFR emancipatória é caraterizada pela divisão justa do trabalho na agroindústria, no cuidado da casa, dos (as) filhos (as) e de idosos (as) entre as mulheres e os homens.

\section{Considerações finais}

As mulheres passam a se sentirem mais empoderadas através das AFR, já que antes muitas delas não tinham efetiva participação na gestão da propriedade e na distribuição da renda. Em todos os casos, a agroindústria promoveu o aumento de autonomia financeira e da autoestima das mulheres envolvidas, embora também tenha aumentado consideravelmente a sua carga de trabalho.

Entretanto, as longas jornadas de trabalho trazidas pela atividade na produção primária, na agroindustrialização, na comercialização dos produtos, no cuidado com a casa e com os filhos etc., prejudicam a qualidade de vida dessas mulheres. É necessário fomentar o modelo de agroindústria com caráter emancipatório para promover uma distribuição justa de trabalhos entre homens e mulheres. Dessa forma, o empoderamento delas será efetivamente potencializado.

Entendemos que todas as AFR estudadas estão contribuindo para a geração de trabalho, renda e autonomia para suas proprietárias e para outras mulheres. O fortalecimento do acesso das AFR aos mercados institucionais desenha-se como uma forma promissora de estimular o processo de empoderamento dessas e de outras mulheres do campo, principalmente se for estimulada a agroindústria familiar emancipatória. 
$\mathrm{O}$ acesso aos mercados institucionais mostra potencialidade para estimular o processo de empoderamento das mulheres envolvidas em AFR. Entretanto, a sobrecarga de trabalho dessas mulheres pode comprometer esse processo. Nesse sentido, o Estado precisa promover melhorias nos programas PAA e PNAE de forma a potencializar as agroindústrias familiares de caráter emancipatório.

Nesse sentido, sugerimos que a operacionalização de políticas públicas que contemplem as AFR seja acompanhada pela distribuição de materiais informativos sobre questões de gênero e especificadamente sobre esse tema. Também sugerimos que a operacionalização dessas políticas seja acompanhada por ações da extensão rural, que trabalhem questões de gênero e promovam discussões grupais sobre a importância da distribuição justa do trabalho na casa e na agroindústria. Dessa forma, efetivamente será potencializado o empoderamento das mulheres na perspectiva de Berth (2018), o empoderamento que está relacionado a se conscientizar e transformar, abarcando o âmbito individual e o coletivo. Temos ciência de que essa questão não é simples, já que vivemos em uma sociedade patriarcal, entretanto é necessário tencionar a mudança, papel que também cabe ao Estado.

\section{REFERÊNCIAS}

BECKER, C.; ANJOS, F. S. São os mercados institucionais da agricultura familiar um instrumento para o desenvolvimento rural? estudo de caso em municípios do sul do Brasil. Rev. Fac. Agron. La Plata (2015) Vol 114 (Núm. Esp.1) Agricultura Familiar, Agroecología y Territorio: 143-152.

BERTH, J. O que é empoderamento? Coleção Feminismos Plurais. Belo Horizonte: Ed. Letramento, 2018.

BONI, V. Agroindústrias Familiares: uma perspectiva de gênero. Anais $30^{\circ}$ Encontro Anual da ANPOCS, 2006.

BRASIL. Lei n ${ }^{\circ}$ 11.947/2009 - PNAE - Programa Nacional de Alimentação Escolar. BRASIL. Programa Nacional de Alimentação Escolar. 2006. Site http://www.fnde.gov.br/index.php/programas/pnae. Acesso em 05/11/2018.

COSTA, C.; MARIN, J. O. B. (Org.) Gênero e Campesinato no Sul do Brasil: Dominação Masculina e Transformação. 1. ed. Curitiba: Editora CRV, 2018.

COSTA, C; NARVAZ, M.G; CAMARGO, K. Violência de gênero em áreas rurais: gritos que ecoam pelo Pampa. In: COSTA, C.; MARIN, J. O. B. (Org.) Gênero e 
Campesinato no Sul do Brasil: Dominação Masculina e Transformação. 1. ed. Curitiba: Editora CRV, 2018, p. 37-62.

DEERE, C. D; LEÓN, M. O empoderamento da mulher: Direitos à terra e direitos de propriedade na América Latina. Porto Alegre/RS: UFRGS ed. PGDR, 2002.

GAZOLLA, M. Agricultura familiar, segurança alimentar e políticas públicas:

Uma análise a partir da produção para autoconsumo no território do Alto Uruguai/RS.

Dissertação de Mestrado. Programa de Pós-graduação em Desenvolvimento

Rural/UFRGS. Porto Alegre, 2004.

MIOR, L. C. Agricultores familiares, agroindústrias e redes de desenvolvimento rural. Chapecó: Editora Argos, 2005.

MIOR, L. C. Agricultores familiares, agroindústrias e território: A dinâmica das redes de desenvolvimento rural no Oeste Catarinense. Tese de doutorado. Doutorado Interdisciplinar em Ciências Humanas - Sociedade e Meio Ambiente/UFSC.

Florianópolis, 2003.

MIOR, L.C. Agricultura familiar, agroindústria e desenvolvimento territorial. In:

VIEIRA, P. F.; CAZZELA, A.; CERDAN, C.; CARRIÈRE, J. P. (Org.).

Desenvolvimento Territorial Sustentável: subsídios para uma política de fomento.

Florianópolis, SC: Associação Brasileira de Pequisa e Ensino em Ecologia e

Desenvolvimento (APED), 2010. p. 235-257.

PAULILO, M. I. Mulheres Rurais. Quatro Décadas de Diálogo. Florianópolis: Ed. da UFSC, 2016.

QUADROS, C. A Participação dos Jovens nas Agroindús-trias Familiares do Litoral Sul Catarinense e as Implicações no Processo Sucessório. Dissertação - Grau de Mestre em Programa de Pós-Graduação em Agroecossistemas da Universidade Federal de Santa Catarina Agroecossistemas. Florianópolis/SC, 2012.

SCHAAF, A.V.D. Jeito de mulher rural: a busca de direitos sociais e da igualdade de gênero no Rio Grande do Sul. Passo Fundo: UPF, 2001.

SCHNEIDER, S. Agricultura Familiar e pluriatividade. Tese de Doutorado em Sociologia apresentada ao PPGS da UFRGS. Porto Alegre: Universidade Federal do Rio Grande do Sul, 1999.

SULZBACHER, A. W.; NEUMANN, P. S. O social e suas dimensões em agroindústrias familiares rurais. Revista Extensão Rural, Santa Maria, v.21, n.3, jul./set. 2014.

VENTURINI, F. E. O. A Diferenciação das Agroindústrias Familiares Rurais e o Desenvolvimento Territorial: do desejado ao real. VII Jornada Interdisciplinar de Estudos Agrários e Agroindustriais - Universidade de Buenos Aires - UBA - Buenos Aires, Argentina - 2011. 
WESZ JUNIOR, W. J.; TRENTIN, I. C. L.; FILIPPI, E. E. Os reflexos das agroindústrias familiares para o desenvolvimento das áreas rurais no Sul do Brasil.

Cuadernos Des. Rural, Bogotá (Colombia), 6 (63): 59-85, julio-diciembre 2009.

YIN, R. K. Estudo de caso: planejamento e métodos. Trad. Daniel Grassi. 2.ed. Porto Alegre: Bookman, 2001. 